\title{
LAS TRADUCCIONES ARGENTINAS DE GALENO: EL CASO DE LA SANGRÍA
}

\author{
Mónica Durán Mañas \\ Universidad de Granada \\ Email: monicaduran@ugr.es \\ ORCID iD: https://orcid.org/0000-0002-3881-1410
}

Recibido: 2 septiembre 2019; Aceptado: 3 julio 2020

Cómo citar este artículo/Citation: Durán Mañas, Mónica (2021) "Las traducciones argentinas de Galeno: el caso de La Sangría", Asclepio, 73(1): p337. https://doi.org/10.3989/asclepio.2021.03

RESUMEN: El presente trabajo estudia las primeras traducciones de Galeno al español que se realizaron en Argentina, en el marco de un proyecto editorial dirigido por Aníbal Ruiz Moreno. La investigación pone de manifiesto que la colección en la que aparecen no era en realidad solo de obras de Galeno, sino una colección general con textos relevantes para la historia de la medicina. Se añade el caso concreto de La sangría como estudio de caso para una evaluación preliminar de la naturaleza de las traducciones ofrecidas por Ruiz Moreno y su equipo. El proyecto quedó inconcluso debido a la repentina muerte de su director por lo que quedaron algunos tratados galénicos sin publicar. El artículo aporta una hipótesis plausible sobre el destino de estas traducciones. Aníbal Ruiz Moreno, fue nada menos que el fundador, junto con Pedro Laín Entralgo, de la revista que hoy se llama Asclepio.

PALABRAS CLAVE: Galeno; Sangría; Traducción; Aníbal Ruiz Moreno; Francisco Vera

\section{TRANSLATIONS OF GALEN IN ARGENTINA: THE CASE OF LA SANGRIA}

ABSTRACT: This paper studies the first translations of Galen's works into Spanish which were made in Argentina, within the framework of an editorial project directed by Aníbal Ruiz Moreno. The study shows that the collection in which they appear did not only publish Galen's treatises. It was rather a general collection with texts relevant to the history of medicine. The specific case of La sangría is added as a case study for a preliminary evaluation of the nature of the translations offered by Ruiz Moreno and his team. This project was left unfinished due to the sudden death of its director, so some Galenic treatises remained unpublished. The article provides a plausible hypothesis about the fate of these translations. Aníbal Ruiz Moreno, was no less than the founder, together with Pedro Laín Entralgo, of the magazine that today is called Asclepio.

KEY WORDS: Galen; Bloodletting; Translation; Aníbal Ruiz Moreno; Francisco Vera

Copyright: (C) 2021 CSIC. Este es un artículo de acceso abierto distribuido bajo los términos de la licencia de uso y distribución Creative Commons Reconocimiento 4.0 Internacional (CC BY 4.0) 


\section{GALENO Y SUS TRADUCCIONES}

Galeno de Pérgamo (ca. 129-216 d. C.) es, después de Hipócrates, el médico mejor conocido de la Antigüedad y, sin duda, el que mayor influencia ha ejercido en la historia de la medicina. Muchas de sus teorías y prácticas, no sin gran debate mediante, permanecieron vigentes hasta bien entrado el siglo XIX. Aunque es obvio que en la actualidad ya no se sostienen teorías como la de los humores o prácticas como la de la flebotomía, tal y como Galeno las concebía, no puede negarse tampoco que la medicina moderna aún bebe de ciertos conceptos galénicos. Así, expresiones como "anastomosis de Galeno", "nervio de Galeno", "cerato de Galeno" o "forma galénica" son solo algunos ejemplos de su pervivencia como tecnicismos en el lenguaje médico de hoy. Su enorme impacto no puede caer en el olvido por más que sus teorías no tengan una utilidad directa en las prácticas terapéuticas del siglo XXI.

Esta es una de las razones por las que diversos grupos de investigación de distintos países dedican sus esfuerzos desde hace algunos años a la traducción de las obras de este prolífico autor, muchas de las cuales han permanecido durante siglos ${ }^{2}$ sin despertar apenas el interés de científicos, traductores e investigadores. Así, en Francia, existe un proyecto de edición de las obras de Galeno en la Collection des Universités de France (CUF) de la editorial Les Belles Lettres, encabezado por Jacques Jouanna y Véronique Boudon-Millot ${ }^{3}$; en Alemania, cabe destacar el proyecto Towards a Galen in English, dirigido por el Dr. Philip van der Eijk de la Universidad Humboldt de Berlín ${ }^{4}$; también la colección Loeb Classical Library publicada por Harvard University Press colabora en este ingente esfuerzo de traducción del Corpus Galenicum; y en España el principal promotor de esta labor traductora es el proyecto de investigación de la Universidad de La Laguna Galeno y sus obras médicas, filosóficas, científicas y literarias, dirigido por el Dr. Luis Miguel Pino Campos ${ }^{5}$. Este proyecto, que es continuación de la labor iniciada en $1986^{6}$ por el Dr. Juan Antonio López Férez, tiene por objetivo traducir la totalidad de las obras de Galeno en lengua española con introducciones, notas e índices de términos griegos y de nombres propios ${ }^{7}$.

Al desinterés por las obras de Galeno durante tanto tiempo ha contribuido significativamente el hecho de que sus contenidos médicos carezcan de vigencia científica. Además, filólogos y traductores se han visto disuadidos de acercarse a sus textos debido a los numerosos errores que contiene la principal edición disponible, la de Carl Gottlob Kühn ${ }^{8}$, quien en el siglo XIX trató de compilar en 20 volúmenes todo el Corpus Galenicum con la intención de preservarlo. Sin poder dejar de reconocer el trabajo que se tomó en ello, pues ha sido de gran utilidad para su propósito inicial ${ }^{9}$, se ha de decir también que sería necesaria una nueva edición crítica del corpus completo en la línea de las que ya se han publicado en la serie Corpus Medicorum Graecorum $(\mathrm{CMG})^{10}$ o en la CUF. En efecto, Kühn tomó una versión griega que ya contenía bastantes errores, la de Chartier, y una latina de época renacentista ${ }^{11}$, quizás la que tuvo más a mano, $y$, pese a introducir correcciones para mejorar el texto, no realizó una exhaustiva tarea de colación de los distintos manuscritos en el sentido que exigiría el rigor científico de hoy. No se trata, por tanto, de una edición crítica y depurada como sería deseable desde un punto de vista filológico. En ello radica su principal problema, de suerte que esta circunstancia añade una dificultad nada desdeñable para quien desee aproximarse al contenido de las obras.

\section{EL PROYECTO EDITORIAL DE ANÍBAL RUIZ MORENO}

Aníbal Ruiz Moreno (1907-1960) fue un activísimo profesor e investigador de la medicina y de su historia, que desarrolló su labor principalmente en Argentina, su país natal ${ }^{12}$. Sus inquietudes le llevaron a darle una dimensión internacional a su trabajo, que fue reconocido en las más distinguidas universidades ${ }^{13}$. Su esmero, su dedicación, su rigor para profundizar en la investigación pusieron de relieve la importancia del estudio de la historia de la medicina incluso para su ejercicio en el presente.

En el año 1938 comienza su carrera universitaria como docente e investigador adscrito a la cátedra de Historia de la Medicina de la Universidad de Buenos Aires, ocupada entonces por el profesor Juan Ramón Beltrán, y en 1947, logra la categoría de Profesor Titular. Fue director de los Archivos Argentinos de Historia de la Medicina (La Plata, 1942-1946) y cofundador con Pedro Laín Entralgo de la revista española Archivos Iberoamericanos de Historia de la Medicina, que nace en 1950 con domicilio en el Consejo Superior de Investigaciones Científicas (CSIC), cuya sede se hallaba en el número 4 de la calle Duque de Medinaceli de Madrid. Del cuidado con que se realizó todo el proceso editorial por parte de los directores de la revista da cuenta Virgilio Paredes Borja, 1950, pp. 129-132, entonces profesor de la Facultad de Medicina de Quito y miembro del consejo editorial. Paredes Borja conoció a Ruiz Moreno en una "una gira por las Américas" que este realizó en junio de 1949 para organizar el Consejo de Redacción ${ }^{14}$. La intención de Ruiz Moreno, señala Paredes, era la de fundar una publicación de carácter semestral centrada en la Historia de la Medicina en 
Iberoamérica, disciplina de gran riqueza, pero de escasa presencia en las publicaciones científicas: "es el momento, nos decía ${ }^{15}$, de dar a conocer lo mucho que se estudia y escribe actualmente sobre la materia". Cuatro años después, el mismo Paredes Borja, 1954, p. 186, con ocasión de la visita a Quito de Pedro Laín Entralgo, por entonces Rector de la Universidad de Madrid, no puede dejar de referirse a la publicación como "la más destacada Revista de la especialidad en Iberoamérica"16. En 1954 esta publicación pasó a llamarse Archivo Iberoamericano de Historia de la Medicina y Antropología Médica y, en 1964, Asclepio, revista en la que el presente artículo ve la luz.

Uno de los grandes proyectos que emprendió Aníbal Ruiz Moreno fue el de traducir el Corpus Galenicum completo para lo cual, tal y como informan García Ballester, 2000, pp. 26-30 y Pino Campos, 2006-2007, pp. 569-571, contó con la colaboración de Julio B. Lafont, Antonio Tovar e Irene Augusta Arias, entre otros. Sin embargo, se sabe muy poco acerca de esta empresa y es necesario recorrer distintas fuentes -periódicos, artículos, catálogos de bibliotecas, repositorios, etc.para hacerse una idea de lo que fue. Así, el Journal of the History of Medicine and Allied Sciences ${ }^{17}$ recoge entre sus eventos más destacados la visita el 29 de mayo de 1959 del profesor Ruiz Moreno al Departamento de Historia de la Medicina de la Facultad de Medicina de la Universidad de Yale e informa de algunos detalles relevantes. Por una parte, indica que en el curso 19451946, cuando Ruiz Moreno enseñaba en la Facultad de Ciencias Médicas de La Plata, fundó allí la Sociedad de Historia de la Medicina y comenzó la publicación de una revista de 18 volúmenes con contenidos tan diversos como traducciones de Galeno, tratados sobre la viruela y estudios sobre el Protomedicato de Buenos Aires, así como una traducción del Regimen sanitatis Salernitanum, llevada a cabo gracias a la colaboración del renombrado médico austríaco Adolfo Weiss. Por otra, informa de que el Departamento al que pertenecía Ruiz Moreno estaba compuesto por un director de estudios, dos traductores de Griego y Latín, un investigador de historia, un investigador general, todos ellos miembros a tiempo completo, y otras cuatro personas encargadas de seminarios, además de un investigador, todos ellos honoríficos. Por tanto, esta noticia sugiere que Ruiz Moreno dirigió una revista que publicó traducciones de Galeno realizadas en el marco de su departamento, compuesto por un equipo multidisciplinar. Pero ¿cuáles fueron esas traducciones y cómo se hicieron? Y, sobre todo, ¿dónde están? Para responder a estas cuestiones, partiré de la traducción de uno de los tres tratados galénicos sobre la flebotomía ${ }^{18}$, De ve- nae sectione adversus Erasistratum ${ }^{19}$, que dará cuenta de la complejidad de este asunto.

\section{EL MISTERIO DE LA SANGRÍA}

La sangría: contra Erasístrato aparece publicada en Madrid en 1970 por Francisco Vera ${ }^{20}$, concretamente en las páginas 887-906 del volumen Científicos griegos II de la editorial Aguilar, obra que constituye un compendio de tratados de diversos autores griegos ${ }^{21}$ relevantes para la historia de la ciencia. En las líneas siguientes, se tratará de aclarar por qué esta traducción no aparece recogida en los repertorios bibliográficos ${ }^{22}$ sobre Galeno, así como de definir cuáles son sus características más notables.

Su título sugiere inmediatamente que se trata de la obra De venae sectione adversus Erasistratum de Galeno. Sin embargo, cuando el lector se acerca a ella se encuentra con dos sorpresas: la primera, que la prosa es bastante más ajustada a la sensibilidad moderna que la del médico de Pérgamo; la segunda, que hay pasajes que no se corresponden con el texto griego transmitido por Kühn. Todo un misterio capaz de despertar la curiosidad de cualquier filólogo.

\subsection{EL TRADUCTOR}

La primera cuestión que debe plantearse es quién es el traductor de La sangría, ya que el propio volumen II, que contiene las obras de Galeno, no lo aclara suficientemente. En efecto, nada más abrir el libro el lector puede apreciar que Científicos griegos se publica como "recopilación, estudio preliminar, preámbulos y notas por Francisco Vera". Pero, en las introducciones ${ }^{23}$ que preceden a las obras de los científicos griegos Vera no dice que sea él mismo el traductor ${ }^{24}$ ni explica tampoco de dónde ha extraído las traducciones que presenta, aunque en muchas de ellas sí da cuenta de las traducciones existentes de estas obras a lenguas modernas ${ }^{25}$. De hecho, en ocasiones se permite incluso introducir una pequeña crítica como la que hace a propósito de la traducción inglesa de las obras de Proclo realizada por T. Taylor (1792): "[...] pero no es una versión directa del griego, sino de la latina de Barozzi, y tiene no solo los defectos de este, sino los que de su cosecha le añadió Taylor". Sobre esta apreciación volveré más adelante.

Por lo que respecta a la compilación de los tratados de Galeno, el propio Vera deja anotado en la introducción que los precede lo siguiente: "Finalmente, Ruiz Moreno ha publicado en La Plata, 1947: Arte médico, Definiciones médicas y Modo de desenmascarar a los simuladores de enfermedades, y en Buenos Aires, 19471956: Procedimientos anatómicos, Los huesos, La disec- 
ción de los músculos para los principiantes, La bilis negra, La sangría y Del conocimiento del pulso" (Vera, 1970b, p. 797). Así pues, Francisco Vera deja entrever en esta introducción que Ruiz Moreno ${ }^{26}$ había publicado en Buenos Aires, entre los años 1947 y 1956, varios tratados de Galeno entre los que se encontraba La sangría. Sin embargo, no es sino en la introducción al volumen I donde aclara que él no es el traductor de estos libros: "Los tratados publicados fueron traducidos por Aníbal Ruiz Moreno (1907-1960), profesor de Historia de la Medicina en la Universidad de Buenos Aires, con la colaboración de la lingüista Irene Augusta Arias, doctora en Filosofía y Letras, y del historiador Julio B. Lafont, doctor en la misma Facultad" (Vera, 1970a, p. 10). Y unas líneas después insiste: "Las traducciones de las obras y fragmentos que no figuran en la lista anterior ${ }^{27}$ han sido hechas por mí, y las notas a pie de página, tanto de las versiones propias, como de las ajenas, son mías y asumo, por consiguiente, la responsabilidad de todas ellas, excepto las de Aristóteles, Dioscórides y Galeno, que pertenecen a sus respectivos autores" (Vera, 1970a, p. 10).

De lo dicho, se deduce que, en el caso de Galeno, Francisco Vera se limita a recoger la traducción y notas de Ruiz Moreno, Augusta Arias y Lafont. El problema principal es que con esta información no es posible saber con exactitud quién es el traductor de cada tratado, pues podría ser cualquiera de los tres, habida cuenta de que trabajaban conjuntamente en un mismo proyecto teniendo cada uno de ellos el encargo de traducir unas obras en particular.

Por otra parte, si alguien trata de hallar las traducciones de Galeno que Francisco Vera, 1970b, p. 797, atribuye a Aníbal Ruiz se encontrará con varias dificultades. La primera de ellas es que las traducciones de Ruiz Moreno disponibles aparecen en las bases de datos bibliográficas ${ }^{28}$ en varias publicaciones que llevan el mismo título de "Obras de Galeno", por lo que es necesario abrirlas físicamente para saber qué tratados contienen. Son concretamente tres, pero en ellas no se encuentran los tratados galénicos que Francisco Vera recoge ${ }^{29}$ :

- Lafont, Julio B. y Ruiz Moreno, Aníbal (1947), Obras de Galeno, traducción y notas por --, La Plata, Universidad Nacional de la Plata, Imprenta López. Contiene las obras Definiciones médicas (pp. 23-80), Sobre el modo de desenmascarar a los simuladores de enfermedades (pp. 81-84) y Arte médico (pp. 85-149).

- Ruiz Moreno, Aníbal (dir.) (1948). Obras de Galeno, vol. XII, tomo I, Buenos Aires, Publicaciones del Instituto de Historia de la Medicina, Talleres Gráficos Argentinos L. J. Rosso. Contiene las obras Compendio del pulso para los estudiantes (pp. 9-31) y De las diferencias de los pulsos (pp. 33-191).

- Ruiz Moreno, Aníbal (dir.) (1956). Obras de Galeno, vol. XVIII, tomo I, Buenos Aires, Publicaciones del Instituto de Historia de la Medicina, Talleres Gráficos de J. Héctor Matera ${ }^{30}$. Contiene la obra Del conocimiento del pulso (pp. 9-117).

Las tres obras contenidas en el volumen publicado por Ruiz Moreno en La Plata, 1947, coinciden con las mencionadas por Vera, aunque en distinto orden ${ }^{31} \mathrm{y}$ con el título de la tercera obra abreviado, (Sobre el) modo de desenmascarar a los simuladores de enfer-

Fotografías 1, 2 y 3. De izquierda a derecha. Lafont, Julio B. y Ruiz Moreno, Aníbal (1947), Obras de Galeno, traducción y notas por --, La Plata, Universidad Nacional de la Plata. Ruiz Moreno, Aníbal (dir.) (1948). Obras de Galeno, vol. XII, tomo I, Buenos Aires, Publicaciones del Instituto de Historia de la Medicina. Ruiz Moreno, Aníbal (dir.) (1956). Obras de Galeno, vol. XVIII, tomo I, Buenos Aires, Publicaciones del Instituto de Historia de la Medicina. Fuente: Ejemplares de la Biblioteca Tomás Navarro Tomás, sala de griego antiguo del CCHS-CSIC, Madrid.
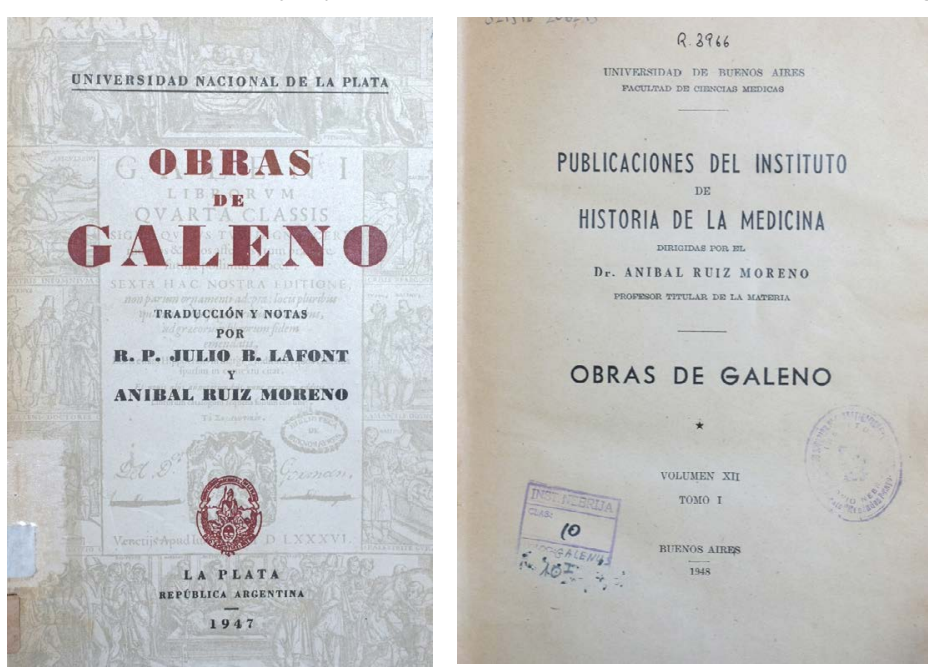

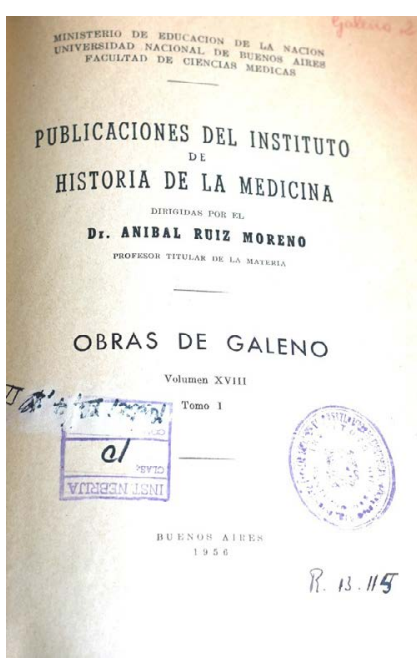


medades, por lo que es posible que el recopilador citara de memoria. Ahora bien, de las restantes obras mencionadas por Vera, solamente Del conocimiento del pulso está recogido en los volúmenes anteriores, de suerte que todavía hay cinco tratados que no se encuentran: Procedimientos anatómicos ${ }^{32}$, Los huesos, La disección de los músculos para los principiantes, La bilis negra y La sangría ${ }^{33}$. En cambio, en el volumen publicado en Buenos Aires, 1948 hay dos obras, Compendio del pulso para los estudiantes y De las diferencias de los pulsos ${ }^{34}$, que Vera no menciona, por lo que no es exhaustivo en su relación de las traducciones de Galeno llevadas a cabo por Ruiz Moreno (ver Tabla I).

El hecho de que se conserven los volúmenes XII y XVIII bajo el título Obras de Galeno invita a pensar que hubo (al menos) $18^{35}$, publicados entre 1948 y 1956 (al menos), que recogían también las obras de las que Vera da cuenta. Con todo, son demasiados para contener solo las obras que cita Vera, por lo que cabría pensar que hubo más. Ahora bien, ¿dónde pueden estar estos libros? O, por delimitar la cuestión, ¿dónde podría estar el volumen que contenía La sangría?

Este panorama, junto con el hecho de que cada una de las traducciones mencionadas fue hecha por Ruiz Moreno en colaboración con otra persona, sugiere que este fue el director de una colección planeada ${ }^{36}$ en el marco del Instituto de Historia de la Medicina de la Universidad de Buenos Aires, lugar donde se publican dos de los volúmenes que se conservan. En efecto, las obras que, según Vera, "Ruiz Moreno ha publicado en La Plata, 1947" son tratados traducidos por el Reverendo Padre Julio B. Lafont y el propio Ruiz Moreno. $Y$ las publicadas en el marco del Instituto de Historia de la Medicina de Buenos Aires están también traducidas por diversos autores. Concretamente, Compendio del pulso para los estudiantes y De las diferencias de los pulsos son obra de Antonio Tovar ${ }^{37}$ y Aníbal Ruiz Moreno; en cambio, la traducción de Del conocimiento del pulso, publicada ocho años después, "ha sido hecha en colaboración con la Profesora Irene Augusta Arias, ayudanta diplomada y traductora de la Cátedra a mi cargo" (Ruiz Moreno, 1948, p. 7), lo cual da a entender que la traducción es de ella con independencia de que Ruiz Moreno y/o Antonio Tovar la revisaran antes de su publicación. La idea de que Ruiz Moreno es el director de un ambicioso proyecto de traducción de la obra galénica se confirma cuando en la "Advertencia" al volumen de 1956 afirma a propósito de la traducción que presenta: "Pensamos hacer lo mismo con los libros que faltan sobre el pulso en los próximos años" (Ruiz Moreno, 1956, p. 7). Pero hay más. Ruiz Moreno fue director de las Publicaciones del Instituto de Historia de la Medicina entre 1948 y $1961^{38}$, años entre los cuales se publicaron nueve números, según informa la profesora Sánchez, 2016, p. 14, en su recorrido por la historia de la Medicina en Argentina. Así, las traducciones de Galeno conservadas vieron la luz en una publicación periódica cuyos números no estuvieron todos dedicados a Galeno, tal y como anunciaba el Journal of

Tabla 1. Obras de Galeno que, según Vera, fueron publicadas por Ruiz Moreno. Fuente: elaboración propia.

\begin{tabular}{|l|l|l|}
\hline \multicolumn{1}{|c|}{ OBRA DE GALENO } & RUIZ MORENO & \multicolumn{1}{c|}{ VERA } \\
\hline Definiciones médicas & La Plata, 1947 & $\begin{array}{l}\text { Solo mencionada } \\
\text { en la introducción }\end{array}$ \\
\hline $\begin{array}{l}\text { Sobre el modo de desenmascarar a los } \\
\text { simuladores de enfermedades }\end{array}$ & La Plata, 1947 & $\begin{array}{l}\text { Solo mencionada } \\
\text { en la introducción }\end{array}$ \\
\hline Arte médico & La Plata, 1947 & $\begin{array}{l}\text { Solo mencionada } \\
\text { en la introducción }\end{array}$ \\
\hline Compendio del pulso para los estudiantes & Buenos Aires, 1948 & - \\
\hline De las diferencias de los pulsos & Buenos Aires, 1948 & - \\
\hline Del conocimiento del pulso & Buenos Aires, 1956 & $\begin{array}{l}\text { Solo mencionada } \\
\text { en la introducción }\end{array}$ \\
\hline Procedimientos anatómicos & - & Madrid, 1970b \\
\hline Los huesos & - & Madrid, 1970b \\
\hline $\begin{array}{l}\text { La disección de los músculos para los } \\
\text { principiantes }\end{array}$ & - & Madrid, 1970b \\
\hline La bilis negra & - & Madrid, 1970b \\
\hline La sangría & - & Madrid, 1970b \\
\hline
\end{tabular}


the History of Medicine and Allied Sciences ${ }^{39}$. En efecto, es posible encontrar, salvando las dificultades que ofrece la inexactitud de fuentes bibliográficas, catálogos y bases de datos, noticias de la existencia de los siguientes volúmenes ${ }^{40}$ :

- XII, tomo 2 (1948), que contiene la traducción del Tratado de la viruela y el Sarampión de Abū Bakr Muḥammad ibn Zakarīyā Rāzī, junto con La sanidad militar en la guerra del Brasil, trabajo conjunto de Aníbal Ruiz Moreno con Vicente Risolía y Rómulo D’Onofrío ${ }^{41}$;

- XIII, tomo $1\left(1949^{42}\right)$, con El ejército del norte y La salud de San Martín ${ }^{43}$, de Aníbal Ruiz Moreno, Vicente Risolía, María Mercedes Allende y Luisa Galimbertí de Carbajo;

- XIII, tomo 2 (1949), con La fundación del Protomedicato de Buenos Aires de Aníbal Ruiz Moreno;

- XIV, tomo 1 (1950), con Homenaje al Libertador General San Martin ${ }^{44}$, de Aníbal Ruiz Moreno, Vicente Risolía, María Mercedes Allende y Galimbertí de Carbajo;

- XIV, tomo $2^{45}$ (1950), con La medicina en la obra de San Isidoro, de Irene Augusta Arias, Antonio Tovar y Aníbal Ruiz Moreno;

- XV, tomo $1^{46}$ (1951), con El régimen sanitario salernitano, de Adolfo Weiss;

- XV, tomo $2^{47}$ (1951), con El juicio de insania de don Ginés de Rabaza, diputado por Valencia al conclave de $J_{a s p e}{ }^{48}$, de Aníbal Ruiz Moreno e Irene Augusta Arias;

- XVII ¿tomo? (1954), Aimé Bonpland; aportaciones de carácter inédito sobre su actividad científica en
América del Sur, de Aníbal Ruiz Moreno, Vicente Risolía y Rómulo D’Onofrío ${ }^{49}$;

- XIX ¿tomo? (1959), Actualización de la obra sanitaria y médico social de Vértiz durante su desempeño en el virreinato del Río de La Plata 1777-178350; de Aníbal Ruiz Moreno, Vicente Risolía y Rómulo D’Onofrío;

- XX, ¿tomo 1? (1961), La palabra de los médicos en las Asambleas de Mayo de 1810, de Vicente Risolía, Rómulo D’Onofrío y Alfonso Díaz Trigo;

- XX, ¿tomo 2? (1961), Acotaciones en torno al primer examen de capacitación médica. Efectuado en Buenos Aires en 1660, trabajo de Aníbal Ruiz Moreno con Vicente Risolía y Alfonso Díaz Trigo ${ }^{51}$.

Así pues, a partir de esta relación es posible entender que: 1. Hasta 1959 vieron la luz, en efecto, los 18 volúmenes que menciona la noticia del Journal of the History of Medicine and Allied Sciences, publicada en ese mismo año (teniendo en cuenta los tiempos de edición, el volumen XIX aún no estaría disponible); 2. Entre 1948 y 1961 se publican, en efecto, 9 volúmenes (del XII al XX), tal y como informa la profesora Sánchez, 2016, p. 14 (9 volúmenes con dos tomos cada uno); 3. Si se añaden a la relación anterior las publicaciones correspondientes a las Obras de Galeno (volúmenes XII, tomo 1 y XVIII, tomo 1), aún faltan los números XVI, tomos 1 y 2; XVII ¿tomo?, XVIII, tomo 2 y XIX ¿tomo?, también ausentes en los testimonios bibliográficos. Tampoco es posible, a partir de las obras que Guerra ${ }^{52}$ relaciona, inferir el contenido de los volúmenes que faltan, ya que las obras sobre Hipócrates, Paré, Baillou, Séneca y Rufo pertenecen a otras colecciones ${ }^{53}$. Además, aunque he podido reconstruir el listado anterior sorteando la falta de consistencia de las fuentes con

Fotografía 4. Izquierda. Traducción de Tectandro (1549). Derecha. Traducción de Tectandro corregida por Agustín Gabaldino (1586). Fuente: BNF Gallica y Google Books.
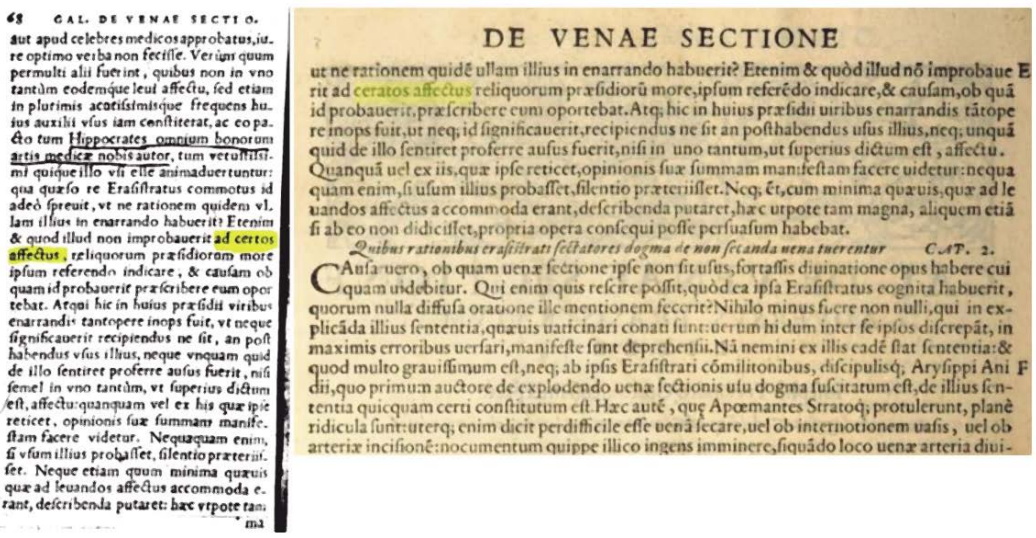
respecto a ciertos datos (año de publicación, título de las obras, etc.), no me ha sido posible localizar físicamente ejemplares de todos los volúmenes ${ }^{54}$. Pese a tratarse de un material valioso, parece que no ha sido suficientemente coleccionado y conservado.

Por otra parte, el obituario publicado por Guerra, 1961, pp. 381-382, informa de que a su muerte Ruiz Moreno dejó algunas traducciones de Galeno sin terminar -no dice cuáles-, así como el tratado De contagionibus de Fracastoro. Sin embargo, esta última obra fue publicada por el Centro de Investigaciones de Historia de la Medicina de la Universidad de Chile en $1962^{55}$, por lo que alguien la tenía en su poder y la trasladó hasta el país vecino para su publicación. Cabe preguntarse si no sucedería lo mismo con esas otras obras de Galeno que quedaron sin terminar. En ese caso, se abriría el interrogante sobre quién lo publica por primera vez, dónde y cuándo.

Con respecto a la traducción de La sangría, que no aparece por ninguna parte, podría pensarse que formaba parte de alguno de los tomos que faltan en mi relación. Quizás un detalle presente en el obituario ${ }^{56}$ de Aníbal Ruiz Moreno publicado por el British Medical Journal pueda ofrecer alguna pista: "He wrote three books about South American medical history -one about mediaeval medicine, one on medicine in Greco-Roman mythology, and one each on the rheumatic diseases in the works of Hippocrates (1941), Sydenham (1943), Baillou (1944), Paré (1944), Celsus (1947), Rufus of Ephesus (1955), and Galen (1956)". Con independencia de la exactitud de la relación de los libros publicados por Ruiz Moreno, pues es evidente que faltan obras -también las mencionadas por
Vera-, es significativo que aquel se ocupara de Galeno en la última etapa de su vida, lo cual podría apuntar a que su precipitado fallecimiento tal vez dejó inconclusos algunos de sus proyectos. De hecho, Vera señala esta circunstancia en su prólogo a propósito de la traducción de la obra galénica: “[...] la versión castellana iniciada en 1947 por el médico argentino Aníbal Ruiz Moreno ha quedado inconclusa a la muerte de este". Pero ¿ podría ser el propio Vera quien los publica por primera vez en Científicos Griegos II y, por este motivo, los llama "publicados" al escribir después el prólogo? Es cuando menos llamativo que Vera recoja unos tratados que no se encuentran en ningún otro lugar. En cualquier caso, con los datos disponibles, no es posible conocer siquiera la autoría de la traducción de $L a$ sangría, ni de los restantes tratados que Vera recopila, ni tampoco cuándo y dónde se publicaron, si es que llegaron a publicarse.

\subsection{LA TRADUCCIÓN}

Como se ha señalado antes, la versión de De venae sectione adversus Erasistratum que aparece en Cientificos griegos es agradable de leer, con una prosa bastante más seductora que la del propio Galeno. Esto es fácil de percibir incluso en las frases más sencillas. Así, ante el eterno dilema del traductor, si ser lo más fiel posible al texto original sin tamizarlo o tratar de acercarlo al lector moderno permitiéndose para ello algunas licencias, aquel parece haberse decantado por la segunda opción. Tal elección no supone un problema siempre que se cumplan dos condiciones fundamentales: la primera, que se advierta qué estrategia de traducción se ha empleado; la segunda y más importante, que el mensaje del texto no se vea alterado. Sin embargo, el problema prin-

Tabla II. Texto y traducciones de De. ven. sect. adv. Erasistr XI. 150.5-9K. Fuente: elaboración propia.

\begin{tabular}{|c|c|}
\hline VERSIÓN & TEXTO \\
\hline Kühn (griego) & $\begin{array}{l}\text { tí dè́ pote pathò̀n ho Erasistratos èmélēse teléōs tòn hypèr autês diexeltheîn } \\
\text { lógon; kaì gàr areskómenon echrên episēmainesthai toîs páthesin autò } \\
\text { prosanagrápsanta, katháper tálla boèthémata, kaì areskoménou eipeîn } \\
\text { aitían di'hè̀n arésketai [XI. } 150.5-9 \mathrm{~K} \text {.] }\end{array}$ \\
\hline Kühn (latín) & $\begin{array}{l}\text { [...] quid tandem Erasistrato accidit, ut prorsus illius meminisse } \\
\text { neglexerit? Etenim num in affectibus quibusdam ipsum adhibere conveniat, } \\
\text { quemadmodum et alia remedia et cur conveniat, causam indicare debebat. }\end{array}$ \\
\hline $\begin{array}{l}\text { Tectandro } \\
\text { (latín) }\end{array}$ & $\begin{array}{l}\text { [...] qua quaeso re Erasistratus commotus id adeo sprevit, ut ne rationem } \\
\text { quidem ullam illius in enarrando habuerit? Etenim et quod illud non } \\
\text { improbauerit ad certos affectus, reliquorum praesidiorum more ipsum } \\
\text { referendo indicare, et causam ob quam id probauerit praescribere eum } \\
\text { oportebat. }\end{array}$ \\
\hline $\begin{array}{l}\text { Vera (español } \\
\text { traducido de la } \\
\text { versión latina de } \\
\text { Tectandro) }\end{array}$ & $\begin{array}{l}\text { [...] yo pregunto cuál fue el motivo por el cual Erasístrato desestimó tanto } \\
\text { este remedio, que ni siquiera lo consideró en sus escritos. Puesto que no lo } \\
\text { desechó, como hizo de los otros remedios contra las enfermedades } \\
\text { enceradas, hubiera debido, al referirse a la sangría, expresar los motivos de } \\
\text { su pensamiento. }\end{array}$ \\
\hline $\begin{array}{l}\text { Durán Mañas } \\
\text { (español } \\
\text { traducido del } \\
\text { griego de Kühn) }\end{array}$ & $\begin{array}{l}\text { Entonces, ¿qué le pasó a Erasístrato que descuidó por completo exponer el } \\
\text { razonamiento sobre él? Pues, si le gustaba, hubiera sido necesario señalarlo } \\
\text { prescribiéndolo para las afecciones, al igual que los demás remedios, y, si } \\
\text { le gustaba, decir la causa por la que le gustaba. }\end{array}$ \\
\hline
\end{tabular}


cipal con la traducción de La sangría es que su contenido no siempre coincide con el del texto griego transmitido.

De este modo, en términos generales se observa que en determinados pasajes la traducción sigue fielmente palabra por palabra el texto griego, pero en otros no. Y, cuando no lo hace, en ocasiones mantiene el sentido subyacente en griego y en otras no. Para fortuna del investigador, el propio texto de la recopilación de Vera, 1970 b, p. 889, ofrece una clave, concretamente en la traducción del pasaje de De venae sectione adversus Erasistratum XI. 150.5-9 K. ${ }^{57}$, donde el término toîs páthesin, "afecciones", se convierte en "enfermedades enceradas" (ver Tabla II). En efecto, la palabra "encerada", de difícil comprensión - ¿cómo puede estar "encerada" una enfermedad?- da paso a la nota 4 que reza: "El texto dice ceratus". Esta nota evidencia que el traductor partió de una traducción latina ${ }^{58}$, probablemente porque no tendría a mano en Argentina un original griego ${ }^{59}$. Pero es claro que esta versión no es la de Basilea que acompaña al texto griego de la edición de Kühn (=Chartier, 1679, p. 393), pues en ella nada se dice de "ceratus". Ahora bien, ¿de qué edición latina puede haber partido? Una revisión de las traducciones al latín del tratado galénico en cuestión ${ }^{60}$ permite observar que la versión presente en Vera, 1970b depende de la versión latina de Tectandro (Josephus Tectander), en Gaudanus y Tectander, 1549, p. 68.

Tectandro, nacido en Cracovia en época de Segismundo I Jagellón el Viejo, rey de Polonia entre los años 1506 y 1548, estudió en su ciudad natal y viajó más tarde a Italia, Alemania y Holanda ${ }^{61}$. Cuando regresó a Po-

Tabla III. Ejemplos de traducciones divergentes. Fuente: elaboración propia.

\begin{tabular}{|c|c|}
\hline TEXTO GRIEGO & TRADUCCIÓN \\
\hline \multirow[t]{2}{*}{$\begin{array}{l}\text { echómenos gàr tồ peri tè̀n } \\
\text { anagōgè̀n ho katà tèn } \\
\text { flegmonèn kíndynos, en hōi } \\
\text { prosphérein mèn ou rháidion } \\
\text { [XI. 149-2-3 K.] }\end{array}$} & $\begin{array}{l}\text { Porque al peligro que deriva del flujo se une el de la } \\
\text { inflamación, que es muy dificil de combatir (Vera, 1970b, p. } \\
888 \text { ). } \\
\text { Fuente latina: Huic enim periculo quod in reiectione accidit, } \\
\text { aliud ex inflammation adhaeret, in quo quidem oferre } \\
\text { aliquid perquam dificile est (Gaudanus y Tectander, } 1549 \text {, } \\
\text { p. 67) }\end{array}$ \\
\hline & $\begin{array}{l}\text { Pues sigue de cerca a la afluencia el peligro de inflamación, } \\
\text { durante el cual no es fácil dar alimentos (Durán Mañas). }\end{array}$ \\
\hline \multirow{2}{*}{ 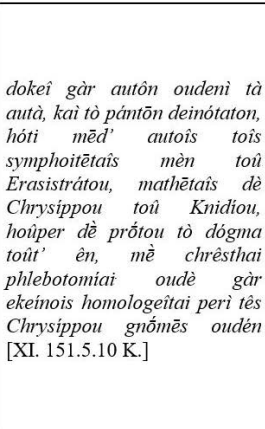 } & $\begin{array}{l}\text { En efecto, ninguno de ellos es del mismo parecer y, lo que } \\
\text { es mucho más grave, ni los compañeros de Erasístrato, ni } \\
\text { los discipulos de Arisipo Anidio [sic], quien fue el primero } \\
\text { en desechar el uso de la sangría, no dicen nada seguro sobre } \\
\text { el parecer de Erasístrato (Vera, } 1970 \mathrm{~b}, \mathrm{p} \text {. 888). } \\
\text { Fuente latina: Nam nemini ex illis eadem stat sententia: et } \\
\text { quod multo gravissimum est, neque ab ipsis Erasistrati } \\
\text { commilitonibus, discipulisque Chrysippi Cnidii, quo primum } \\
\text { autore [sic] de explodendo venae sectionis usu dogma } \\
\text { suscitatum est, de illius sententia quicquam certi } \\
\text { constitutum est. (Gaudanus y Tectander, 1549, p. 69) }\end{array}$ \\
\hline & $\begin{array}{l}\text { Pues ninguno de ellos tiene la misma opinión, y lo peor de } \\
\text { todo, ni siquiera entre los propios compañeros de estudios } \\
\text { de Erasístrato y los discípulos de Crisipo de Cnido, cuyo } \\
\text { primer dogma era este: no utilizar la flebotomía. Pues ni } \\
\text { siquiera entre ellos hay ningún consenso sobre la opinión de } \\
\text { Crisipo (Durán Mañas). }\end{array}$ \\
\hline
\end{tabular}

Ionia, fue bien recibido por el gobernador y pronto fue nombrado secretario y médico ${ }^{62}$ de la corte de Isabel, hija del rey Segismundo. Tras la publicación de De venae sectione adversus Erasistratum en Galeni Opera Omnia a cargo de Andrea Cratandro (1536) y Jerónimo Froben (1542) en las imprentas de Jacobo Giunta, cinco años después de su muerte, en 1549, se publicó en Basilea su traducción al latín de De venae sectione adversus Erasistratum y De venae sectione adversus Erasistrateos Romae degentes, junto con otras obras de Galeno traducidas por Gaudano ${ }^{63}$. Pero el texto latino de Tectandro presenta "certus", no "ceratus", por lo que la nota denuncia, en realidad, una errata particular presente en la edición que maneja el traductor. Esta errata se encuentra en la p. $5 v$ de la sexta edición Giunta publicada por Giovanni Costeo en 1586, que contiene la traducción de Tectandro corregida por Agustín Gadaldino ${ }^{64}$. Así pues, el traductor, a quien debe suponerse asimismo autor de la nota, es bien consciente de que unas "enfermedades enceradas" son difíciles de encajar en el contexto del discurso galénico y, por este motivo, siente la necesidad de justificar la traducción dejando constancia de su fidelidad al texto que tiene delante.

Pese a que sería necesario cotejar con detenimiento la traducción al español y la traducción latina de la que parte para valorar su exactitud, de lo que no cabe duda a tenor de lo visto es de que el contenido y la forma de la versión latina ya varía considerablemente del texto griego ${ }^{65}$. De este modo, no es difícil imaginar que, hecha una traducción de otra traducción, el resultado no puede ser otro que el de la tergiversación, al menos en determinados pasajes de la obra. Sería interesante realizar este análisis en profundidad para tomar verdadera consciencia de cómo el lector que no puede acceder a los textos en su versión original permanece a menudo "engañado" por textos que, aunque agradables de leer, no dicen verdaderamente lo que sus autores originales pretendieron.

\section{CONCLUSIÓN}

Varias reflexiones surgen inevitablemente a tenor de este pequeño viaje por una parte de la transmisión de la medicina galénica. De un lado, cabe destacar que el origen y condición de los traductores del siglo XX no se reduce al ámbito de la filología -como ahora-, ni de la medicina -como antes-, ni tampoco de la iglesia, sino de todos ellos a la vez: Ruiz Moreno era médico, especialista en reumatología; Vera, matemático; Antonio Tovar, filólogo; Julio B. Lafont, sacerdote e historiador, e Irene Augusta Arias, lingüista. Conforman, de este modo, un equipo interdisciplinar con un amplio conocimiento de las lenguas clásicas como denominador 
común. Este punto de partida supone un gran acierto, pues la tarea de traducir bien a Galeno precisa de grupos multidisciplinares que permitan profundizar en los textos y apreciar sus distintos matices interpretativos.

De otro lado, por lo que respecta a la traducción de La sangría, pese a todas las personas que se han implicado en su búsqueda en el transcurso de mi investigación, a las cuales van dirigidos mis agradecimientos más sinceros, no ha sido posible localizarla. $Y$ puesto que no aparece ninguna noticia antes de Vera, creo que es muy probable que formara parte de esas obras de Galeno que quedaron inconclusas y que no llegaron a publicarse debido al fallecimiento prematuro del director del proyecto, en el que Vera insiste. En este caso, de modo semejante a como sucedió con la traducción de Fracastoro, habría llegado a manos de Vera, quien la habría publicado cuando finalmente vio la oportunidad, junto con la obra de otros autores. Esta hipótesis se hace extensiva a las cinco obras galénicas publicadas por Vera, que se habrían originado en el marco de esta colección generalista más ambiciosa, conformando un episodio más en la historia del trabajo editorial sobre los textos de Galeno. Esto explicaría que no aparezcan recogidas en la Bibliographie der galenischen und pseudogalenischen Werke.

Quedan así interrogantes abiertos, habituales en la historia de la transmisión textual, pero a menudo inesperados cuando se trata de materiales más recientes: no solo no se sabe cómo llegó la publicación que contenía el tratado La sangría hasta Vera, sino que ni siquiera se conoce qué miembro del equipo lo tradujo. En cualquier caso, traduce fielmente, hasta el punto de reproducir las erratas de una traducción latina.

Por último, pese a que, como se ha visto a propósito de la traducción de Proclo hecha por T. Taylor, Vera

\section{NOTAS AL FINAL}

1 El presente trabajo se inserta en el marco del Proyecto FFI2017-82850-R (AEI/FEDER, UE), Galeno y sus obras médicas, filosóficas, literarias y científicas. Periodo de vigencia: 01-01-2018 a 31-12-2020. Ha sido realizado durante una estancia de investigación en el Instituto de Lenguas y Culturas del Mediterráneo y Oriente Próximo (CSIC).

2 Como señala el profesor Nutton, 2008, p. 355, en los últimos 30 años sus obras se han estudiado con mayor atención que en ningún otro momento desde el siglo XVII. A este interés han contribuido, en gran medida, nuevos descubrimientos de traducciones medievales de obras perdidas, así como el hallazgo de nuevos textos como el del manuscrito Vlatadon 14, encontrado casualmente en 2005 por el entonces estudiante de doctorado Antoine Pietrobelli en el monasterio de Vlatadon en Salónica. Vid. critica que las versiones de textos griegos a lenguas modernas se hagan a través de traducciones latinas, no duda en incluir en su recopilación traducciones de Galeno que arrancan de una versión latina -sin aludir siquiera al hecho-, por lo que debió tener una poderosa razón para hacerlo. Ello sugiere una voluntad manifiesta de publicar las traducciones de Ruiz Moreno. Esta circunstancia debe crear, al menos, dos alertas en el lector: la primera y común a toda traducción, que debe tomarse con cautela cualquier texto que no sea leído en su idioma original, incluso cuando renombrados médicos o filólogos avalen las ediciones; la segunda, que, en el caso de leer una traducción, el lector debe informarse bien de su procedencia para poder valorarla en su justa medida.

Aunque, por fortuna, la medicina actual no dependa de la correcta interpretación de los textos galénicos, no cabe duda de que constituyen un valioso testimonio para la historia de la medicina y, por este motivo, merecen ser transmitidos, aunque sea en traducciones, con el mayor esmero. En cualquier caso, la traducción debe entenderse como un proceso diacrónico, debido, por una parte, a la propia naturaleza cambiante de las lenguas y, por otra, a los nuevos hallazgos o perspectivas que pueden explorarse. Queda, pues, mucha tarea por hacer.

\section{AGRADECIMIENTOS}

Quiero agradecer a Juan Rodríguez Somolinos, Inmaculada Pérez Martín, Juan Antonio López Férez, Luis Miguel Pino Campos, Pablo Adrián Cavallero, Pablo Toribio Pérez, Pedro Bádenas de la Peña y, muy especialmente, a Emilio Regueira Vera, nieto de Francisco Vera, sus comentarios y apoyo en el proceso de elaboración de este trabajo. Para la revisión del artículo, las sugerencias de los evaluadores anónimos han sido de un valor incalculable. Gracias.

Boudon-Millot y Jouanna, 2010; Kotzia y Sotiroudis, 2010; Manetti, 2012; Singer, 2013; Rothschild y Thompson, 2014, y Petit, 2018.

3 Vid. Jouanna y Boudon-Millot, 1993, pp. 101-135.

4 Este proyecto posee una útil y actualizada página web disponible en https://www.klassphil.hu-berlin.de/en/ avh-professur/projects/towards-a-galen-in-english (consultado el 05/05/2021)

5 Ya el filólogo Donaciano Martínez Vélez emprendió a principios del siglo XX un proyecto de traducción de las obras médicas griegas con el apoyo de un grupo de médicos españoles encabezados por Federico Rubio y Galí. Este proyecto no se completó y, unos años más tarde, Aníbal Ruiz Moreno proyectó en Argentina la traducción completa del Corpus Galenicum, empresa que quedó igualmente inconclusa, como se verá más adelante. También Carlos García 
Gual, como director de la Biblioteca Clásica Gredos, proyectó traducir la totalidad de las obras galénicas, pero solo cinco volúmenes vieron la luz. Vid. García Ballester, 2000, pp. 26-30 y 38 y Pino Campos, 2006-2007, pp. 569-571.

6 En este año comenzó el primer proyecto Obras de Galeno: medicina y pensamiento (PB-85-0078), financiado por la extinta Comisión Asesora de Investigación Científica y Técnica (CAICYT).

7 Otros proyectos, aunque no tienen como objetivo principal la traducción, llevan a cabo relevantes actividades en torno a la obra del médico de Pérgamo, entre otros autores. Así, en Alemania, la Academia de Ciencias de Berlín-Brandeburgo alberga el proyecto Corpus Medicorum Graecorum (CMG) dirigido por el Dr. Christian Brockmann de la Universidad de Hamburgo, en el marco del cual se realiza una magnífica labor de edición, a veces con traducciones (sin olvidar otros esfuerzos editoriales como el Galenic Scripta Minora publicado en la serie Teubner); en Holanda, se desarrolla el proyecto Human Nature: Medical and Philosophical Perspectives in the Work of Galen of Pergamum, dirigido por el Dr. Teun Tieleman (página web del proyecto: https://projectgalen.sites.uu.nl, consultado el 15/05/20); y en España el proyecto La medicina hipocrática y sus continuadores: estudios filológicos, dirigido por el Dr. Jesús Ángel Espinós de la Universidad Complutense de Madrid aborda aspectos igualmente sustanciosos de la medicina galénica. Cabe asimismo destacar la labor que realiza el Grupo UMR 8167 Orient et Méditerranée. Equipe Médecine grecque et littérature technique, unidad mixta de Investigación actualmente dirigida por Alessia Guardasole en la que participan el CNRS y la Université de Paris-Sorbonne.

8 Carl Gottlob Kühn (1754-1840) fue un médico alemán que desarrolló un gran interés por la historia de la medicina. Editó obras de Areteo de Capadocia, Hipócrates y Galeno. Vid. Nutton, 2002, p. 1.

9 Pese a la magnífica labor que Kühn realizó, ha sido a menudo atacado por los numerosos errores presentes en su edición de Galeno. Sin embargo, estos ataques parecen más bien el fruto de un acercamiento descontextualizado a lo que pretendió y pudo hacer con los medios, materiales y humanos, de los que disponía. Vid. Nutton, 2002, pp. 1-7.

10 CMG empieza a publicarse en 1908. Pueden consultarse sus títulos en su página web http://cmg.bbaw.de/publications/ publikationen-cmg (consultado el 15/05/20).

11 Para una recopilación de las traducciones latinas renacentistas de Galeno, vid. Durling, 1961.

12 De acuerdo con el obituario de Guerra, 1961, p. 381, nació en la provincia de Córdoba.

13 Guerrino, 1962, p. 3, da testimonio del impulso que Ruiz Moreno dio a la Historia de la Medicina en Argentina, sin dejar de lado al mismo tiempo la práctica médica centrada fundamentalmente en el reumatismo. En este sentido, el propio Ruiz Moreno afirmaba que su Departamento había recopilado unos 10.000 documentos de historia de la medicina procedentes de archivos nacionales, provinciales, municipales y eclesiásticos. Vid. Guerra, 1959, p. 384.

14 Este consejo estuvo finalmente compuesto por autoridades de España, Portugal, Argentina, México, Perú, Brasil, Uruguay y Guatemala.

15 Son palabras textuales de Paredes Borja, 1950, pp. 129-130, refiriéndose a Aníbal Ruiz Moreno.
16 Y añade: "Y que buena falta nos hacía, porque hasta muy entrado este siglo, monografías, tratados y revistas de Historia de la Medicina nos venían de tratadistas alemanes, ingleses, norteamericanos, franceses e italianos, que poco se venían cuidando de tocar el destacado papel de España en la evolución de los conocimientos médicos y el de las Repúblicas americanas de habla española".

17 Vid. Guerra, 1959, pp. 383-384.

18 Pese a la influencia que la flebotomía ha tenido durante siglos y el interés de estos tratados para comprender este fenómeno, apenas hay traducciones a lenguas modernas. La más reciente, publicada en 1986 en inglés por Peter Brain bajo el título Galen on Bloodletting -que arranca de su tesis doctoral Galen on venesection (1971)- está acompañada de notas e introducciones que tratan de examinar el origen, desarrollo y validez actual de los postulados galénicos sobre el remedio. Con anterioridad, Ronald Fred Kotrc, 1970 tradujo el segundo tratado, también en inglés, que fue objeto de su tesis doctoral Galen's on Phlebotomy against the Erasistrateans in Rome. Esto es todo. La primera traducción de estos tratados del griego al español con introducción, notas e índices ha visto recientemente la luz en la editorial Ediciones Clásicas como resultado de las actividades del mencionado proyecto de investigación Galeno y sus obras médicas, filosóficas, científicas y literarias.

19 Es convención filológica citar las obras griegas no por sus títulos originales, sino en latín.

20 Francisco Vera Fernández de Córdoba (1888 Alconchel, Badajoz-1967 Buenos Aires, Argentina) fue profesor Catedrático en la Universidad de Buenos Aires, donde llevó a cabo una importante actividad. Su labor como matemático, historiador y filósofo de la ciencia, además de periodista y divulgador, ha sido escasamente conocida en España, pese a su contribución a la historia de la ciencia. Condenado a muerte en su país natal por coherencia con sus propias ideas, hubo de exiliarse a finales de enero de 1939 llegando a la ciudad de Buenos Aires en abril de 1944, tras pasar por Francia, Colombia y la República Dominicana. Para más detalles sobre su vida y obra, vid. Pecellín Lancharro, 1988, pp. 1-179; Cobos Bueno y PeceIlín Lancharro, 1997, pp. 507-528; Vaquero Martínez y Cobos Bueno, 1999, pp. 569-588; Luengo Martínez y Cobos Bueno, 2000, pp. 1-9; Cobos Bueno, 2003, pp. 57-82; Cobos Bueno, 2004, pp. 157-172; Carapeto Sierra, Cobos Bueno y Pulgarín Guerrero, 2005, pp. 171-190.

21 El volumen I recoge obras de Pitágoras, Hipócrates, Demócrito, Platón, Aristóteles, Teofrasto, Eudemo de Rodas, Euclides y Aristarco; el II, obras de Arquímedes, Apolonio de Pérgamo, Eratóstenes, Nicandro, Hiparco, Teodosio de Trípoli, Herón de Alejandría, Dioscórides, Ptolomeo, Galeno, Nicómaco de Gerasa, Pappo, Diofanto de Alejandría y Proclo de Licia.

22 El más especializado y actualizado es, sin duda, el que Gerhard Fichtner iniciara en 1997 consistente en una recopilación de la bibliografía de las obras galénicas y pseudogalénicas. Pese a su fallecimiento en 2012, cada año sigue publicándose puntualmente gracias a la labor del proyecto de investigación Galen of Pergamon: The Transmission, Interpretation and Completion of Ancient Medicine dirigido por el Dr. Christian Brockmann de la Universidad de Hamburgo. Vid. Fichtner, 2019.

23 A la traducción de los tratados de cada científico griego le precede una breve introducción. 
24 Así lo ponen también de manifiesto las recensiones a la obra, como la de Arenzana Hernández y Arenzana Romeo, 2001, pp. 121-124, que puede leerse en la Revista Suma: "Francisco Vera ha seleccionado de la obra inmensa de la ciencia griega textos en los que estos autores manifiestan sus opiniones sobre las matemáticas en general, la geometría, la aritmética, la astronomía, la cosmografía, etc.".

25 Apenas menciona otras traducciones al español porque no las había.

26 Según el obituario publicado el 15 de julio de 1961 en el British Medical Journal (pp. 179-180), Aníbal Ruiz Moreno fue durante 25 años profesor de Historia de la Medicina en la Facultad de Medicina de la Universidad de Buenos Aires, además de uno de los reumatólogos más relevantes de Argentina, con una amplia actividad en este campo. Falleció repentinamente mientras daba clase a sus estudiantes el 22 de diciembre de 1960 a la edad de 56 años. Vid. https://bit.ly/2UluzC2 (consultado el 15/05/20).

27 En esa lista ha mencionado a cinco autores -Aristóteles, Dioscórides, Galeno, Hipócrates, Nicandro y Platón-, dejando claro de qué traducciones es responsable y de cuáles no.

28 Así sucede en las principales bases de datos consultadas como REBIUN, WorldCat, Karlsruher Virtueller Katalog, etc. Curiosamente, la Bibliografía del Doctor Aníbal Ruiz Moreno recopilada por Antonio Alberto Guerrino en 1962 solo recoge el volumen de La Plata, 1947.

29 Dado que en cada volumen participan distintas personas, encontrando sus traducciones, sería fácil determinar de quién es la traducción que ofrece Vera.

30 Tampoco a través de las imprentas es posible averiguar más, dado que desaparecieron. Talleres Gráficos de J. Héctor Matera desarrolló su actividad entre 1950 y 1974 y Talleres Gráficos Argentinos L. J. Rosso, entre 1887 y 1960. La Imprenta López (Buenos Aires, 1908-1969) comenzó siendo un pequeño taller de impresión fundado por José López García (Vélez-Málaga, 1877-Rosario, 1945) y tres décadas después había crecido exponencialmente gracias a la efervescencia cultural de la época en Argentina hasta contar con 182 empleados. Manuel López Soto (Buenos Aires, 1911-1969) tomó el relevo a don José en la dirección de la imprenta durante el boom editorial de los años 40 convirtiendo a la Imprenta López en un punto clave en la dinamización y renovación del libro argentino. Información extraída de la exposición viajera Cómo se imprime un libro: Grafistas e impresores en Buenos Aires 1936-1950 (abril 2017-junio 2019), publicitada en el enlace https://bit. ly/34fwgWi (consultado el 15/05/20).

31 Arte médico, Definiciones médicas y Modo de desenmascarar a los simuladores de enfermedades (Ruiz Moreno, 1947) vs. Definiciones médicas, Sobre el modo de desenmascarar a los simuladores de enfermedades y Arte médico (Vera, 1970b).

32 López Salvá, 2002, p. 68 en su introducción al tratado Procedimientos anatómicos, que traduce para la editorial Gredos, se hace eco de esta circunstancia: "En español, J. Lafont y A. Ruiz Moreno en Obras de Galeno (Buenos Aires, 1948) realizaron la traducción de una selección de obras anatómicas de Galeno, cuya edición original no nos ha sido posible manejar. Ha sido reeditada en España por F. Vera en Científicos griegos (Madrid, 1970) [...]".

33 Estas son las obras que Vera incluye en Científicos griegos, siguiendo este mismo orden.
34 Vid. Pino Campo, 2010, p. 28.

35 Esta cifra coincide con el número de volúmenes de la revista de cuya publicación informa el Journal of the History of Medicine and Allied Sciences. Vid. n. 17.

36 De hecho, la reseña de Sigerist, 1948, pp. 224-225, ya anuncia que se trata del primer resultado de un ambicioso proyecto: "Indeed Julio B. Lafont and Anibal Ruiz Moreno plan nothing less tan a Spanish translation of the complete works of Galen, and the volumen under review is merely a first instalment".

37 Antonio Tovar (1911-1985) fue profesor de griego en la Universidad de Buenos Aires a donde llegó tras la Guerra Civil cuando, como dice su entrada en el Diccionario biográfico español, "rompió con el régimen de Franco" y "comenzó un exilio voluntario en 1958". Allí entró en contacto con estudiosos relevantes de la medicina griega que convivieron con Aníbal Ruiz Moreno en un intenso marco de ebullición intelectual. Vid. http://dbe.rah.es/biografias/9021/antonio-tovar-llorente (consultado el 17/05/20).

38 Aunque Ruiz Moreno falleció en 1960, su última publicación vio la luz al año siguiente.

39 Todas las obras que menciona la noticia -traducciones de Galeno, tratados sobre la viruela y estudios sobre el Protomedicato de Buenos Aires, así como una traducción del Regimen sanitatis Salernitanum- aparecen en la relación siguiente. Vid. nn. 17 y 35.

40 Los volúmenes anteriores, publicados entre 1938 (vol. I) y 1947 (vol. XI), están recogidos como "Publicaciones de la Cátedra de Historia de la Medicina" bajo la dirección del profesor Juan Ramón Beltrán, antecesor de Ruiz Moreno en la Cátedra. La Academia de Medicina de Buenos Aires señala que las Publicaciones del Instituto de Historia de la Medicina, de las que se publicaron los volúmenes $12-20$ entre 1948 y 1961, fueron continuación de las Publicaciones de la Cátedra de Historia de la Medicina. Vid. https://t.ly/zKBq y https:// acamedbai.org.ar/2017/revistas/ (consultados el 15/05/20).

41 Este volumen puede consultarse en la National Library of Medicine de acuerdo con la información disponible en su catálogo virtual https://bit.ly/32iNtMD (consultado el 15/05/20).

42 Kohn Loncarica, Sánchez y Trujillo 2002, p. 8, señalan que este volumen se publicó en 1950, pero debe tratarse de un error, ya que el volumen XIII, tomo 2 es del año 1949 y el tomo 1 ha de ser anterior. Es posible que la confusión parta de que El ejército del norte se publicó al año siguiente, en 1950, en la revista La semana médica, 57, pp. 373-383. Parece que también La salud de San Martín se publicó de nuevo en Buenos Aires en 1950 en una revista llamada EI día médico. Vid. Cremades, 2007, p. 93.

43 Guerrino, 1962, p. 7, recoge esta obra como La salud de San Martín, si bien Kohn Loncarica, Sánchez y Trujillo 2002, p. 8, la citan con el título de Patología de San Martín. Cabe la posibilidad de que Alberto Guerrino hubiera cometido un lapsus al citar de memoria, pues él mismo publicó una obra homónima, La salud de San Martín. Ensayo de patografía histórica (1999). Con todo, Cremades, 2007, p. 93 también cita La salud de San Martín en la revista El día médico (1950).

44 Esta obra es referenciada por Lastres, 1951, 109, n. 1, si bien no menciona sus autores, que pueden hallarse a través del catálogo en línea de la biblioteca londinense The Wellcome Library https://bit.ly/2ZvAOca (consultado el 15/05/20).

45 Hay un ejemplar de este tomo en la Biblioteca Tomás Navarro 
Tomás del CSIC http://biblioteca.cchs.csic.es (consultado el 28/05/20).

46 Existen copias de este volumen en la biblioteca de la Universidad de Navarra https://innopac.unav.es/recor$d=-b 1398233 *$ spi (consultado el 28/05/20), en la Biblioteca Tomás Navarro Tomás del CSIC (http://biblioteca.cchs.csic. es, consultado el $28 / 05 / 20$ ) y en la Biblioteca de la AECID (http://t.ly/wMlg), según sus respectivos catálogos en línea consultados el 28/05/2020, aunque sus datos de identificación no siempre se encuentran correctamente recogidos.

47 Existe una copia de esta obra en la biblioteca de la Universidad de Yale, según su catálogo en línea https://bit.ly/2HCHLxi (consultado el 15/05/20).

48 Vid. Guerrino, 1962, p. 7. Esta obra aparece reeditada un año después en Archivos Iberoamericanos de Historia de la Medicina 6. pp. 3-39.

49 Vid. Kohn Loncarica, Sánchez y Trujillo 2002, p. 8, quienes informan de la existencia de un ejemplar mimegrafiado de $158 \mathrm{pp}$.

50 Guerrino, 1962, p. 7 y Kohn Loncarica, Sánchez y Trujillo 2002, p. 8, informan de la existencia de un ejemplar mimegrafiado de $140 \mathrm{pp}$.

51 Vid. Kohn Loncarica, Sánchez y Trujillo 2002, p. 8.

52 Vid. Guerra, 1961, pp. 381-382: “Ruiz Moreno published several monographs devoted to medical knowledge relating to rheumatism in works by Hippocrates (1941), Sydenham (1943), Paré (1944), Baillou (1944), St. Isidore (1950), Seneca (1954), and Rufus (1954)". The local scene was by no means neglected, and in other works Ruiz Moreno described the fight of the Jesuits to reduce alcohol intoxication during the Colonial Period (1939), the introduction of vaccination to America (1945 and 1947), and the work of the Protomedicate in Buenos Aires (1949). He produced further monographs on General San Martin (1950), Aimé Bonpland (1950), and Vertiz (1959), and on a medical analysis of the Spanish mediaeval Corpus Juris Civilis (1956)".

53 Vid. Guerrino, 1962.

54 Cuando he logrado encontrar un ejemplar lo he señalado en nota.

55 Vid.RuizMoreno,1962yhttps://web.archive.org/web/20190222 003815/http://www.historiacienciaytecnologia.com/historia -de-la-ciencia/historia-de-la-medicina/ (consultado el 05/05/ 2021)

56 Vid. nota 26.

57 Volumen XI, p. 150, líneas 5-9 de la edición de Kühn.

58 También la traducción de las obras de Galeno contenidas en el volumen de Lafont y Ruiz Moreno, 1947, parten de una traducción latina, la "Sexta Edición Giunta, Venecia 1586", según señalan sus autores en p. 7, por ser la versión que tenían a mano en la Biblioteca Nacional. Informan asimismo de que la traducción latina de Sobre el modo de desenmascarar a los simuladores

\section{BIBLIOGRAFÍA}

Autor desconocido (1961), "Obituario. Aníbal Ruiz Moreno, M.D.", British Medical Journal, pp. 179-180, [en línea], disponible en https://bit.ly/2UluzC2 (consultado el 15/05/2020).

Arenzana Hernández, Víctor; Arenzana Romeo, Javier (2001), "La matemática griega", Suma 36, pp. 121-125, [en línea], disponible en https://bit.ly/2ZIz9eD (consultado el 15/05/2020).

Bentkowski, Felix (1814), Historya literatury polskiey: wystawiona w spisie dzieł drukiem ogłoszonych, vol. 2, Varsovia y Vi- de enfermedades de la que parten es obra de Juan Fichard de Francfort y la de Arte médico, de "Nicolás Leoniceno, según la versión hecha sobre antiguos ejemplares griegos, por Agustín Gadaldino" (Lafont y Ruiz Moreno, 1947, p. 85). No hay razones para creer que Ruiz Moreno empleara versiones latinas porque no sabía griego, ya que el volumen de 1956, aunque conserve los títulos de los capítulos que aparecen en la VI edición Giunta, "por ser acertados", sí está traducido directamente del griego de la edición de Kühn (20 vols., Leipzig 1821-1833), "que hemos conseguido por gentileza del Dr. Ricardo Caballero, profesor titular de Historia de las Doctrinas Médicas, de la Facultad de Ciencias Médicas del Rosario. La utilización del texto griego, nos da mayor seguridad de exactitud". Sin duda, bajo tan detallado reconocimiento subyace un infinito agradecimiento por haber podido disponer de materiales de difícil acceso.

59 En el catálogo de la Biblioteca Nacional Mariano Moreno de Argentina sigue sin haber actualmente un solo volumen de Kühn (https://catalogo.bn.gov.ar, consultado el 15/05/20) ni tampoco en el de la Universidad de Buenos Aires (http:// www.sisbi.uba.ar/, consultado el 15/05/20).

60 Curiosamente, la web sobre las versiones latinas de Galeno que coordina y dirige Stefania Fortuna (www.galenolatino. com) no recoge ninguna traducción latina de este tratado.

61 Tectandro escribió en latín tres elegías sobre sus viajes, dedicadas a Petrus Kmita (1477-1553), gran patrono de la cultura en Varsovia, publicadas por Ungler en 1942. Vid. Bentkowski, 1814, p. 443 y Kowalska, 2003, pp. 313-314.

62 Sobre la actividad de Tectandro como editor también de obras médicas contemporáneas, vid. Gilly, 1985, p. 256.

63 Estas versiones se encuentran recogidas en el repertorio de Durling, 1961.

64 Así lo señala el encabezamiento de la traducción: Galeni De venae sectione adversus Erasistratum liber losepho Tectandro Cracoviensi interprete denuo ab Augustino Gadaldino ad Graecorum exemplarium fidem emendatus. Vid. https://bit. ly/2lzGSx6 (consultado el 15/05/20). Esta versión no se recoge en Durling, 1961.

65 Incluso las traducciones directas adolecen a menudo de falta de correspondencia con el texto original, bien debido a licencias para mejorar el atractivo de la traducción, bien a ambigüedades del propio texto que ofrecen distintas posibilidades de interpretación, bien a que el traductor no ha entendido adecuadamente el texto. De este modo, entre diversos traductores de un mismo texto pueden existir notables divergencias, tal y como se aprecia en el comentario de Pino Campos, 2006, p. 1, a propósito de la traducción de Ruiz Moreno del tratado galénico Acerca de la diferencia de los pulsos, de la que dice "estar realizada sobre la misma edición y en la que se tiene en cuenta el texto griego, aunque no siempre".

Ina, Zawadzkiego i Komp, p. 830, [en línea], disponible en https://bit.ly/2ZG6elh, consultado el 28/08/2019.

Bietenholz, Peter; Deutscher, Thomas Brian (eds.) (2003), Contemporaries of Erasmus: a Biographical Register of the Renaissance and Reformation, vol. 1, Toronto-Búfalo-Londres, University of Toronto Press, p. 479.

Boudon-Millot, Véronique ; Jouanna, Jacques (2010), Galien, Oeuvres, tome IV: Ne pas se chagriner, París, Les Belles Lettres, p. 302. 
Brain, Peter (1986), Galen on Bloodletting: A Study of the Origins, Development and Validity of his Opinions, with a Translation of the Three Works, Cambridge, Cambridge University Press, p. 189.

Carapeto Sierra, Cristina; Cobos Bueno, José María; Pulgarín Guerrero, Antonio (2005), "El exilio argentino de Francisco Vera Fernández de Córdoba". En: Casas Sánchez, José Luis y Durán Alcalá, Francisco (coord.), Los exilios en España (siglos XIX y XX): III Congreso sobre el Republicanismo, vol. 2, Priego de Córdoba, Patronato Niceto Alcalá-Zamora y Torres, pp. 171-190.

Casas Sánchez, José Luis; Durán Alcalá, Francisco (coord.) (2005), Los exilios en España (siglos XIX y XX): III Congreso sobre el Republicanismo, vol. 2, Priego de Córdoba, Patronato Niceto Alcalá-Zamora y Torres, p. 705.

Chartier, René (ed.) (1679), Operum Hippocratis Coi et Galeni Pergameni archiatron tomus $X$, Paris, André Pralard, p. 727, [en línea], disponible en https://bit.ly/2ZF7dbt (consultado el 28/08/2019).

Cobos Bueno, José María; Pecellín Lancharro, Manuel (1997), "Francisco Vera Fernández de Córdoba, historiador de las ideas científicas". En: Llull: Revista de la Sociedad Española de Historia de las Ciencias y de las Técnicas, 20, pp. 507-528.

Cobos Bueno, José María (2003), "La Asociación Española de Historiadores de la Ciencia: Francisco Vera Fernández de Córdoba". En: Llull: Revista de la Sociedad Española de Historia de las Ciencias y de las Técnicas, 26, pp. 57-82.

Cobos Bueno, José María (2004), "Francisco Vera Fernández de Córdoba", Ábaco: Revista de cultura y ciencias sociales, 42, pp. 157-172.

Costeo, Giovanni (1586), Galeni Librorum Sexta Classis De cucurbitulis, scarificationibus, hirudinibus, et phlebotomia praecipuo artis remedio tradit, Venecia: Giunta, p. 42, [en línea], disponible en https://bit.ly/2lzGSx6 (consultado el $15 / 05 / 20)$

Cremades, Norma Acerbi (2007), "Un poncho en el museo histórico", Revista de salud pública, 11(2), pp. 89-93, [en línea], disponible en https://bit.ly/2LjQsh4 (consultado el 26/08/2019)

Diels, Hermann Alexander (1905), Die Handschriften der antiken Ärzte I, Berlin: Akademie der Wissenschaften, p. 300, [en línea], disponible en: https://bit.ly/2Zu3VNj (consultado el 09/08/2019).

Durán Mañas, Mónica (en prensa), Galeno. Sobre la flebotomía contra Erasistrato. Sobre la flebotomía contra los erasistrateos en Roma. Sobre la curación mediante la flebotomía, introducción, traducción, notas e índices de --, Madrid: Ediciones Clásicas.

Durling, Richard Jasper (1961), "A Chronological Census of Renaissance Editions and Translations of Galen", Journal of the Warburg and Courtauld Institutes, 24, pp. 230-305.

Fichtner, Gerhard (2019), Corpus Galenicum. Bibliographie der galenischen und pseudogalenischen Werke, compilado inicialmente por Gerhard Fichtner † y posteriormente ampliado, Berlin, Berlin-Brandenburgische Akademie der Wissenschaften, p. 225, [en línea], disponible en: https://bit. Iy/2NLjDfY (consultado el 08/08/2019).

García Ballester, Luis (2000), “Un Hipócrates olvidado: las traducciones castellanas de Donaciano Martínez Vélez (fl. 1900)", Cronos, 3/1, pp. 13-46.
Gaudanus, Theodoricus Gerardus ; Tectander, Josephus (trad.) (1549), Claudii Galeni De curandi ratione per sanguinis missionem liber; ejusdemque de hirudinibus, revulsione, cucurbitula et scarificatione libellus. [Gaudano interprete] De venae sectione adversus Erasistratum librum, De venae sectione adversus Erasistrataeos qui Romae degebant [Tectandro interprete], Lyon, Gulielmus Rouillius, p. 160, [en línea], disponible en: https://bit.ly/2UoneS5 (consultado el 28/08/19).

Gilly, Carlos (1985), Spanien und der Basler Buchdruck bis 1600 Ein Querschnitt durch die spanische Geistesgeschichte aus der Sicht einer europaischen Buchdruckerstadt, Basilea-Fráncfort del Meno: Helbing and Lichtenhahn.

Guerra, Francisco (1959), “Dr. Anibal Ruiz Moreno and the History of Medicine in Buenos Aires", Journal of the History of Medicine and Allied Sciences, 14/7, pp. 383-384.

Guerra, Francisco (1961), “Obituary: Aníbal Ruiz Moreno (19071960)", Bulletin of the History of Medicine, 35/4, pp. 381382.

Guerrino, Antonio Alberto (1962), Bibliografía del Doctor Aníbal Ruiz Moreno, Santiago de Chile, Centro de Investigaciones de Historia de la Medicina de la Universidad de Chile.

Hankinson, Robert James (ed.) (2008), The Cambridge Companion to Galen, Cambridge, Cambridge University Press, $\mathrm{p}$. 450.

Jouanna, Jacques ; Boudon-Millot, Véronique (1993), "Présentation du projet d'édition de Galien dans la Collection des Universités de France", Bulletin de l'Association Guillaume Budé, 2, pp. 101-135, [en línea], disponible en: https://bit. ly/34gxtwm (consultado el 15/05/20).

Kohn Loncarica, Alfredo G.; Sánchez, Norma Isabel; Trujillo, José María (2002), "La obra histórica de Vicente A. Risolía (18931962)", Médicos y Medicina en la Historia, 1(4), pp. 5-12, [en línea], disponible en: http://www.fmv-uba.org.ar/comuni$\mathrm{dad} /$ revistasylibrosdigitales/medicos\&medicinas/Revista-4. pdf (consultado el 28/08/19).

Kotrc, Ronald Fred (1970), Galen's on Phlebotomy against the Erasistrateans in Rome (Galeni De venae sectione adversus Erasistrateos Romae degentes), tesis doctoral, Universidad de Washington, p. 506.

Kotzia, Paraskevi; Sotiroudis, Panagiotis (2010), “Г $\alpha \lambda \varepsilon v$ voú $\Pi \varepsilon \rho i$ à \uriac", Hellenika, 60, pp. 63-148.

Kowalska, Halina (2003), "Tectander". En: Bietenholz, Peter y Deutscher, Thomas Brian (eds.), Contemporaries of Erasmus: a Biographical Register of the Renaissance and Reformation, vol. 1, Toronto-Búfalo-Londres, University of Toronto Press, pp. 313-314.

Kühn, Carl Gottlob (ed.) (1821-1830), Claudii Galeni Opera Omnia XI, Leipzig, Officina Libraria Caroli Cnoblochii, p. 899.

Lafont, Julio B.; Ruiz Moreno, Aníbal (1947), Obras de Galeno, traducción y notas por, La Plata, Universidad Nacional de la Plata, p. 151

Lastres, Juan Bautista (1951), "La medicina en la época de la emancipación", Anales de la Facultad de Medicina, 34(2), pp. 99-124, [en línea], disponible en: https://revistasinvestigacion.unmsm.edu.pe/index.php/anales/article/view/9522 (consultado el 15/05/2020).

López Salvá, Mercedes (2002), Galeno. Procedimientos anatómicos, Madrid, Biblioteca Clásica Gredos. 
Luengo González, Ricardo; Cobos Bueno, José María (2000), Francisco Vera. Los historiadores de la matemática española, edición facsímil editada en España por, Badajoz, Federación Española de Sociedades de Profesores de Matemáticas, p. 220.

Manetti, Daniela (ed.) (2012), Studi sul De indolentia di Galeno, Pisa-Roma, Fabrizio Serra Editore, p. 128.

Nutton, Vivian (2002), "In Defence of Kühn”, Bulletin of the Institute of Classical Studies. Supplement, 77, pp. 1-7.

Nutton, Vivian (2008), "The Fortunes of Galen”. En: Hankinson, R.J. (ed.), The Cambridge Companion to Galen, Cambridge, Cambridge University Press, pp. 355-390.

Paredes Borja, Virgilio (1950), "Archivos Iberoamericanos de Historia de la Medicina", Revista de la Facultad de Ciencias Médicas (Quito), 1 (2), pp. 129-132, [en línea], disponible en: https://t.ly/3oo7 (consultado el 25/05/2020).

Paredes Borja, Virgilio (1954), "El Rector Magnífico de la Universidad de Madrid", Revista de la Facultad de Ciencias Médicas (Quito), 5 (1-4), pp. 185-189, [en línea], disponible en: https://t.ly/tuAZ (consultado el 25/05/2020).

Pecellín Lancharro, Manuel (1988), Francisco Vera Fernández de Córdoba, Badajoz, Departamento de Publicaciones de la Excma. Diputación Provincial de Badajoz, p. 179.

Petit, Caroline (ed.) (2018), Galen's Treatise 'De indolentia' in Context. A Tale of Resilience, Leiden, Brill, p. 296.

Pino Campos, Luis Miguel (2006), “Observaciones al tratado de Galeno Acerca de la diferencia de los pulsos", Fortunatae, 17, pp. 99-115.

Pino Campos, Luis Miguel (2006-2007), Reseña a “GALENO: Sobre la composición de los medicamentos según los lugares. (Libro II). Introducción, traducción, notas e índices de Germán Santana Henríquez. S. P. Universidad de Las Palmas de Gran Canaria, 2005, 157 pp.", Philologica Canariensia, 12-13, pp. 569-571, [en línea], disponible en: https://bit.ly/2LIEbZr (consultado el 15/05/2020).

Pino Campos, Luis Miguel (2010), Sobre la diferencia de los pulsos, Madrid, Ediciones Clásicas, p. 313.

Rothschild, Clare Komoroske; Thompson, Trevor Wade (eds.) (2014), Galen's 'De indolentia': Essays on a Newly Discovered Letter, Tübingen, Mohr Siebeck, p. 336.

Ruiz Moreno, Aníbal (dir.) (1948), Obras de Galeno, vol. XII, tomo I, Buenos Aires, Publicaciones del Instituto de Historia de la Medicina, p. 204.

Ruiz Moreno, Aníbal (dir.) (1956), Obras de Galeno, vol. XVIII, tomo I, Buenos Aires, Publicaciones del Instituto de Historia de la Medicina, p. 125.

Ruiz Moreno, Aníbal (trad.) (1962), Girolamo Fracastoro. Del contagio, de las enfermedades contagiosas y su curación, Santiago de Chile, Centro de Investigaciones de Historia de la Medicina de la Universidad de Chile.

Sánchez, Norma Isabel (2016), “Maneras de hacer Historia de la Medicina argentina. Breves consideraciones (19161936-2016)", Revista de historia de la medicina y epistemología médica, 8(1), pp. 1-40, [en línea], disponible en: https://t.ly/1WrZ (consultado el 15/05/20).

Sigerist, Henry Ernest (1948), Reseña a “Obras de Galeno. Traducción y notas por R. P. Julio B. Lafont y Aníbal Ruiz More- no. La Plata, 1947, 149 p.”, Bulletin of the History of Medicine 22, pp. 224-225.

Singer, Peter Nicholas (2013), Galen. Psychological Writings, Cambridge, Cambridge University Press, p. 558.

Tovar Larrueca, Consuelo, (s.f.), "Antonio Tovar Llorente”, Real Academia de la Historia, Diccionario Biográfico electrónico, [en línea], disponible en: http://dbe.rah.es/ biografias/9021/antonio-tovar-llorente (consultado el: 17/05/20).

Vaquero Martínez, José Manuel; Cobos Bueno, José María (1999), "Matemáticas y exilio: la primera etapa americana de Francisco Vera", Llull: Revista de la Sociedad Española de Historia de las Ciencias y de las Técnicas, 22, pp. 569-588.

Vera, Francisco (1970a), Científicos griegos I, Madrid, Aguilar, p. 998.

Vera, Francisco (1970b), Científicos griegos II, Madrid, Aguilar, p. 1190.

\section{WEBGRAFÍA}

Academia Nacional de Medicina de Buenos Aires (s.f.). Revistas. https://acamedbai.org.ar/2017/revistas/

Biblioteca AECID (s.f.). El régimen sanitario salernitano. http://t.ly/wMlg

Biblioteca Nacional Mariano Moreno (s.f.). https://catalogo.bn.gov.ar Biblioteca Tomás Navarro Tomás (s.f.). http://biblioteca.cchs.csic.es

Catalogo delle traduzioni latine di Galeno (s.f.). www.galenolatino. com

Corpus Medicorum Graecorum (s.f.). Publications. http://cmg. bbaw.de/publications/publikationen-cmg

https://projectgalen.sites.uu.nl

National Library of Medicine Catalog (s.f.). Del contagio, de las enfermedades contagiosas y su curación. https://www.ncbi. nlm.nih.gov/nlmcatalog/101763

National Library of Medicine Catalog (s.f.). Tratado de la viruela y el Sarampión. https://bit.ly/32iNtMD

Ramón (2017). Cómo se imprime un libro: Grafistas e impresores en Buenos Aires 1936-1950. https://bit.ly/34fwgWi

Real Academia de la Historia (s.f.). http://dbe.rah.es

Saldaña, Juan José y Díaz Molina, Libertad (s.f.). Historia de la medicina argentina en la enseñanza de la medicina, Entrevista del Ciclo "Historia de la ciencia local ¿para qué?». https://web.archive.org/web/20190222003815/http:// www.historiacienciaytecnologia.com/historia-de-la-ciencia/ historia-de-la-medicina/ (consultado el 05/05/2021).

Sistema de Bibliotecas y de Información de la Universidad de Buenos Aires (s.f.). http://www.sisbi.uba.ar/

The Wellcome Library (s.f). https://bit.ly/2ZvAOca

Towards a Galen in English (s.f.). https://bit.ly/2LoVGYM

Ulysse (s.f.). Publicaciones de la Cátedra de Historia de la Medicina. https://t.ly/zKBq

Universidad de Navarra (s.f.). Catálogo conjunto. https:// innopac.unav.es/record=b1398233*spi

Yale University Library Catalog (s.f.). https://beinecke.library.yale. edu/library-catalogs-databases (consultado el 05/05/2021) 